\title{
Alterations in Nitric Oxide Synthase in the Aged CNS
}

\author{
Junyang Jung, Changhyun Na, and Youngbuhm Huh \\ Department of Anatomy, College of Medicine, Kyung Hee University, Heoki-Dong 1, Dongdaemun-Gu, \\ Seoul 130-701, Republic of Korea \\ Correspondence should be addressed to Youngbuhm Huh, ybhuh@khu.ac.kr
}

Received 13 February 2012; Revised 3 May 2012; Accepted 5 June 2012

Academic Editor: Marcos Dias Pereira

Copyright () 2012 Junyang Jung et al. This is an open access article distributed under the Creative Commons Attribution License, which permits unrestricted use, distribution, and reproduction in any medium, provided the original work is properly cited.

\begin{abstract}
Aging is associated with neuronal loss, gross weight reduction of the brain, and glial proliferation in the cortex, all of which lead to functional changes in the brain. It is known that oxidative stress is a critical factor in the pathogenesis of aging; additionally, growing evidence suggests that excessive nitric oxide (NO) production contributes to the aging process. However, it is still unclear how NO plays a role in the aging process. This paper describes age-related changes in the activity of NADPH-diaphorase (NADPHd), a marker for neurons containing nitric oxide synthase (NOS), in many CNS regions. Understanding these changes may provide a novel perspective in identifying the aging mechanism.
\end{abstract}

\section{Introduction}

During normal aging, the brain changes morphologically and functionally in terms of brain weight, protein quantity, number of neurons, and neurotransmitter synthetic enzyme concentrations, leading to impairments and changes in sleep patterns, emotions, appetite, neuroendocrine function, exercise, and memory $[1,2]$. Reactive oxygen species (ROS) have particularly deleterious effects on the nervous system because the brain is relatively deficient in antioxidant systems [3]. It is widely believed that the long-term effects of oxidative stress drive aged-related deficits in brain function [4]. This aging process, which is related to the effects of increased oxidative damage, is thought to involve the production of free radicals [5], including superoxide $\left(\mathrm{O}_{2}{ }^{-}\right)$, hydrogen peroxide $\left(\mathrm{H}_{2} \mathrm{O}_{2}\right)$, nitric oxide (NO), and peroxynitrite $\left(\mathrm{ONOO}^{-}\right)$[1]. In particular, the diffusible gas, $\mathrm{NO}$, is involved in essential functions of the central nervous system (CNS), including neurotransmitter release, synaptic plasticity, and the regulation of neuronal electrical activity $[6,7]$; it is also associated with learning and memory in both the cerebrum and cerebellum $[1,8]$. NO plays a significant role in both normal aging and neurodegenerative processes $[9,10]$. Increased NO production during aging suggests that $\mathrm{NO}$ may contribute to the aging process [10-12]. Although these free radicals do not have deleterious effects on the human body in a general environment, the enhanced production of NO aggravates aging process in the CNS [1]. Mitochondria and nitric oxide synthase (NOS) are two major sources of free radicals [13]. To identify the effects of NO in aging, various studies have been made use of nicotinamide adenine dinucleotide phosphate-diaphorase (NADPH-d) histochemistry, which is a simple and selective method for the visualization of neurons containing NOS [14]. In this paper, we highlight the age-related changes in NOS in many CNS regions via several NADPH-d immunohistochemistry studies.

\section{NADPH-d-Positive Neurons}

$\mathrm{NO}$ is produced by the oxidation of L-arginine through NOS using NADPH-d as the electron donor [15]. NADPH$\mathrm{d}$ histochemical staining has been used to identify neuronal NOS ( $n$ NOS) because many studies show that NADPHd may correspond to $n$ NOS $[16,17]$. Thus, NADPH-d is a specific histochemical marker for NOS in the brain $[18,19]$, and NADPH-d-positive neurons have been used to evaluate NO-positive neurons [20]. NOS-immunoreactive (IR)/NADPH-d-positive neurons have been localized in the brain structures of various mammalian species. Many studies have shown the presence of NO and NOS expression in several aging brain areas, such as the cerebral cortex [21], cerebellum [22], amygdala [23], hippocampus [16], striatum [21], tegmental nuclei [24], and periaqueductal gray [25]. 
To varying degrees, $n$ NOS has been colocalized with choline acetyltransferase in the basal forebrain and brainstem [26]. Excessive NO production has been shown to be associated with some neurotoxic and neurodegenerative characteristics during aging [27]. Some studies have suggested that $\mathrm{NADPH}$-d-positive neurons are relatively resistant to various neurodegenerative diseases such as Alzheimer's disease [28, 29] and Huntington's disease [30], and to toxic insults such as $N$-methyl-d-aspartate (NMDA) agonist [31, 32] and quinolinic acid [32, 33]. Unger and Lange [29] reported that there was no significant reduction in the number of NADPH-dpositive neurons in the amygdala and temporal cortex of aged humans although Benzing and Mufson [28] demonstrated an increased number of NADPH-d-positive neurons within the substantia innominata of Alzheimer's disease patients. In many studies, age-related changes in the NADPH-d-positive neurons had different significances in different regions of the brain. Thus, the significance of increased or decreased numbers of NADPH-d-positive neurons in aged rats remains unclear because, in studies by our group, increased NOSIR/NADPH-d-positive neurons increased resistance to the aging process more than neurodegenerative events in brain $[15,34]$.

\section{Regional Changes in NADPH-d in the Aging Brain}

Thomas and Pearse determined that neurons with high NADPH-d activity existed and were dispersed throughout the cerebral cortex and basal ganglia [35]. In this section, we will briefly review the age-related alterations that occur in various CNS regions.

3.1. NOS and the Auditory System. In the central auditory nervous system, auditory information is delivered from the cochlear nucleus $(\mathrm{CN})$ to the superior olivary complex, lateral lemniscus, inferior colliculus (IC), medial geniculate body (MGB), and auditory cortex (AC), in that order. Of these structures, the auditory cortex is considered the most important for hearing. To identify the mechanism of aging in the auditory system, various studies suggested the involvement of oxidative stress in auditory processing. In the central auditory system, age-related changes in NOSIR/NADPH-d-positive neurons were found in the cochlea [36], the superior olivary complex [37], the inferior colliculus (IC) [38], and the auditory cortex (AC) [39]. In previous studies, a significant increase in NADPH-d-positive neurons was reported in the superior olivary nucleus in aged hamsters [37] and rats [40]. Sánchez-Zuriaga et al. showed evidence of a decreased area of NADPH-d-positive neurons in the dorsal cortex (DC) of the IC and an agerelated loss of NADPH-d-positive neurons in the IC and primary cortical auditory area $(\mathrm{Te} 1)$ in rats [41]. These changes were related to hearing impairments associated with increasing age. Our group showed that the number of NADPH-d-positive neurons in the inferior colliculus was significantly increased in aged rats (Figure 1), whereas the area of NADPH-d-positive neurons in all regions did not

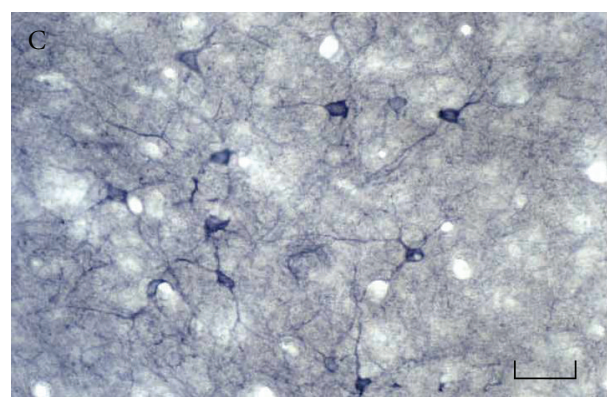

(a)

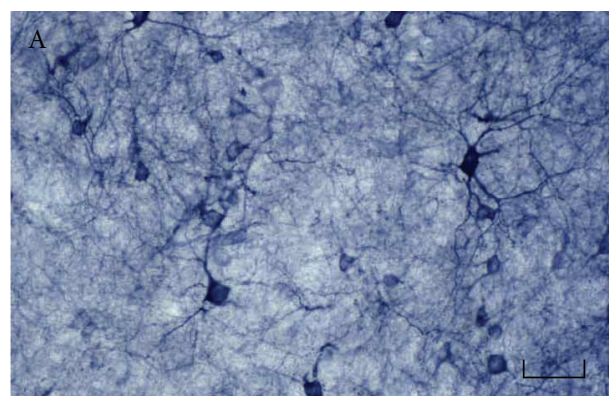

(b)

FIGURE 1: NADPH-d-positive neurons in the rat inferior colliculus. The number of NADPH-d-positive neurons in the inferior colliculus was significantly higher in aged than in younger rats. NADPH-dpositive neurons are dark purple. Frozen sections of $40 \mu \mathrm{m}$ thickness were made in the coronal plane. The histochemical detection for NADPH-d activity was performed as follows: after free-floating sections were incubated for $10 \mathrm{~min}$ at room temperature in $0.05 \mathrm{M}$ Tris buffer ( $\mathrm{pH} 8.0$ ), sections were incubated for $60 \mathrm{~min}$ at $37^{\circ} \mathrm{C}$ in the $0.05 \mathrm{M}$ Tris buffer containing $0.3 \%$ (v/v) Triton X-100, $0.1 \mathrm{mg} / \mathrm{mL}$ nitroblue tetrazolium, and $1.0 \mathrm{mg} / \mathrm{mL} \beta$-NADPH. C: control; A: aged rat. Scale bar $=50 \mu \mathrm{m}$. Modified from Huh et al. [42].

differ significantly between aged and younger rats [42]. Thus, age-related alterations in the NADPH-d-positive neurons of the auditory system may be region-specific.

Interestingly, $\mathrm{NO}$ has been reported to inhibit the activity of $N$-methyl-D-aspartate (NMDA) receptors, reducing the effects of glutamate and inducing changes in neural transmission [43]. This reduction in NMDA receptors (NMDARs) expression may be involved in the change of synaptic plasticity driven by the age-related decease in sensory input, resulting in age-related impairment in the function of the NMDAR/NO signaling pathway in the CNS [44]. However, in our study, the expression of NMDARs was increased in the $\mathrm{CN}, \mathrm{MGB}$, and $\mathrm{AC}$ during aging, although it was found that the expression of NMDARs was decreased in the superior olivary nucleus and IC [45]. Thus, these findings also indicated that age-related changes in the NMDARs in the central auditory system were region-specific.

Another interesting observation was the activation of voltage-gated $\mathrm{K}^{+}$currents through excessive $\mathrm{NO}$ production in rat auditory cortical neurons [46]. In a previous study, NO-stimulated potassium channels induced longterm potentiation in slices prepared from the rat auditory cortex layer IV [47]. Using patch-clamp electrophysiology, 
our group evaluated the effects of $\mathrm{NO}$ on modulating $\mathrm{K}^{+}$ currents by assaying for NADPH-d, a marker of NOS, and by examining the effects of S-nitro- $N$-acetylpenicillamine (SNAP), an NO donor. The modulatory effects of NO on the $\mathrm{K}^{+}$currents of acutely isolated rat auditory cortical neurons showed gradual increases in the $\mathrm{K}^{+}$currents [46]. This NO-induced activation of $\mathrm{K}^{+}$currents hyperpolarizes the membrane potential of a neuron, inhibiting neuronal excitability. The increased $\mathrm{NO}$ activation of $\mathrm{K}^{+}$currents suppress neuronal activity in the auditory cortex. Therefore, excessive NO production may be involved in the hearing impairment caused by aging.

3.2. NOS and the Visual System. In the visual system, retinal ganglion cells project to the lateral geniculate nucleus (LGN) of the thalamus. Visual input is delivered from the retina and the occipital cortex to the ventral lateral geniculate nucleus (vLGN), a thalamic visual nucleus, of the rat [48]. During normal aging, visual function decreases partly because of neural changes in the retina and central visual pathways. Ahmad and Spear [49] suggested that aging produced a statistically significant reduction in neuron density in both the magnocellular and parvicellular layers, which are parts of the visual system, although there was no significant loss of neurons. Uttenthal et al. [50] observed a several fold increase in NOS-positive bands in aged rats using Western blotting of brain extracts. In the rat vLGN, most NADPH-d-positive neurons are geniculotectal projection neurons, although a smaller proportion acts as local circuit inhibitory neurons [51]. Yu et al. [40] showed a significant enhancement in NADPH-d activity in the supraoptic nucleus of aged rats. Villena et al. showed a decrease in the number of NADPH-dpositive neurons in aged old rat vLGN compared with controls [17]. Our group showed that the number of NADPH-dand $n$ NOS-positive neurons did not change significantly in the dorsal LGN (dLGN) and vLGN of aged rats. Additionally, no age-related changes were observed in the superior colliculus. The staining intensities of NOS-IR/NADPH-dpositive neurons increased significantly in the dLGN and vLGN aging processes [52]. However, although each group published different results characterizing NAPDH-d-positive neurons in the central visual system all, these results showed that increased NO production may be associated with alteration in visual function during aging. Further studies are required to clarify this relationship between NADPH-dpositive neurons and $n$ NOS in age-related changes in central visual system.

3.3. NOS and Spinal Cord. During advanced aging, the pelvic visceral organs physically and functionally changes. The lower lumbar and sacral spinal cord are essential for controlling the function of the bowel, bladder, and sexual organs [53]. Ranson et al. reported that the dorsal commissural nucleus $(\mathrm{DCN})$ and the intermediolateral nuclei (ILN) of the lumbosacral spinal cords in aged rats exhibit significant decreases in neurotransmitter levels [54]. Yoon et al. reported that a reduction in the number of $n$ NOS-IR neurons occurred in the central autonomic nucleus and the superficial dorsal horn of the spinal cord in aged rats [55]. The number of NADPH-d-positive neurons in the motor nucleus at the L4-L6 levels of the spinal cord decreased in aged rats [56]. Tan et al. found that NADPH-d-positive neurons are present in the lumbosacral spinal cords of aged rats. However, no colocalization of NADPH-d-positive and $n$ NOS-IR neurons was detected in the lumbosacral spinal cords of aged rats [57]. Thus, NADPH-d activity does not always coincide with the NO-containing neural structures, and NADPH-d function in spinal cord is also unclear.

3.4. NOS and Hormones. Magnocellular neurosecretory neurons in the rat supraoptic nucleus (SON) have been found to synthesize oxytocin (OXY) in the dorsal part and the arginine vasopressin (AVP) in the ventral region [58]. OXY is a mammalian hormone that functions as a neuromodulator in the brain. OXY is best known as a reproduction-related hormone, facilitating childbirth and breastfeeding after childbirth. Arginine vasopressin (AVP), also known as antidiuretic hormone $(\mathrm{ADH})$, is a neurohypophysial hormone produced in most mammalian brains. AVP is responsible for increasing the effective circulating volume by increasing water absorption, water permeability, reabsorption, and peripheral vascular resistance. Yu et al. observed no significant agerelated changes in the number of the OXY-IR/NADPH-dpositive neurons in the dorsal part of the SON, but they did observe an age-related increase in NADPH-d-positive neurons in the SON [40]. Because the concentration of OXY in the plasma decreased in aged rats [59], it is thought that the age-related increase in the NADPH-d-positive neurons may inhibit the secretion of the OXY and reduce the concentration of OXY in the plasma. The AVP-expressing neurons exhibited an increased area in the SON of aged rats [60]. Yu et al. confirmed this increase and the existence of AVP-IR/NADPH-d-positive neurons in aged rats [40]. However, because the circulating levels of AVP did not change in aged rats compared with young rats [61], this result corresponded to inhibition of the secretion of AVP by NO in NOS-expressing neurons [62].

Neuropeptide Y (NPY) is a widely distributed neurohormone associated with food intake [63] and the release of gonadotrophins [64]. NOS colocalizes with both somatostatin and neuropeptide Y (NPY) in the corpus striatum and the cerebral cortex $[65,66]$. During aging process, the decrease in NPY levels in neural tissues is drastic [67, 68]. Our group demonstrated that, in the aged group, the number of NPY-IR/NADPH-d-positive neurons did not significantly decrease in the cerebral cortex and striatum compared to the control group. However, the number of NPY-IR/NADPH-d-negative neurons significantly decreased in all cerebral cortical areas, except the nucleus accumbens, and the caudatoputamen in the aged group [21]. In a study of aged Fischer 344 rats, which are more resistant to aging than other rats strain $[69,70]$, the aged group showed that the number of NPY-IR/NADPH-d-positive neurons did also not significantly change in all regions of the cerebral cortex compared to the control group [71]. However, 
the number of NPY-IR/NADPH-d-negative neurons significantly decreased in the frontal association, primary motor, secondary somatosensory, insular, ectorhinal, perirhinal and auditory cortexes in the aged group [71]. These studies demonstrated that the NADPH-d containing NPY-IR neurons in the cerebral cortex and striatum of rats were less influenced by aging than those of the control. Therefore, the relative stability of the selective population of NPYIR/NADPH-d-positive neurons within the cerebral cortex and striatum helped protect against atrophy during aging.

Vasoactive intestinal polypeptide (VIP) is a peptide hormone produced in the suprachiasmatic nuclei (SCN) of the hypothalamus in the brain $[72,73]$. The SCN is the specific location of the "master circadian pacemaker," an area that daily modulates timekeeping in the body. VIP plays an important role in the communication between individual brain cells in this area [74]. Andreose et al. [75] suggested that there is a marked decrease in VIP-IR in the cerebral cortex and other brain regions in rats during the aging process. Chee et al. [76] reported that the size of VIP-IR neurons in the suprachiasmatic nucleus of the aged rats increased in comparison with that of controls. Our group showed that VIP and NADPH-d did not coexist in any single neuron in the cerebral cortex of either group [77]. However, a significant decrease was found in the number of VIP-IR/NADPH-d-negative neurons in the cerebral cortex of aged rats. This selective depletion and atrophy of VIPIR neurons from the cerebral cortex of aged rats shows an increased vulnerability of VIP-IR neurons to the aging process compared with NADPH-d-positive.

3.5. NOS and the Salivary System. Salivary secretion is controlled by the combined action of the parasympathetic and sympathetic nervous system. Several areas of the SON and the limbic system, which influence the endocrine and autonomic nervous systems, participate in the regulation of water and sodium balance [78, 79]. Inhibition of salivary secretion during aging has been demonstrated in rats [80], and many reports have demonstrated that NO influences the regulation of salivary secretion $[81,82]$. In the SON and the medial septal area of rats, NOS-expressing neurons were identified, and NO-related inhibition of salivary secretion was demonstrated $[83,84]$. Tanaka et al. showed that cell number, cell size and reactive density of the NADPH-dpositive neurons significantly increased in the SON of aged rats [85]. These results suggest an inhibitory role of $\mathrm{NO}$ in salivary secretion during aging. However, there are not many studies which have contributed to evaluating the inhibitory role of NO in salivary secretion in age-related changes.

3.6. NOS and Stress. The periaqueductal gray (PAG) surrounding the cerebral aqueduct is important for the organization of responses to stress and pain. NADPH-d is well represented in the neurons of the dorsolateral neuronal column of the periaqueductal gray (dlPAG) [86]. Lolova et al. demonstrated that, with aging, the total dendritic length of NADPH-d-positive neurons was increased, and the total cell number in the dlPAG was significantly decreased [87].
Several stress models using immobilization, cold and hot stimuli in wild-type rats increased NOS expression [88] and the number of NADPH-d neurons in the PAG [89]. Smalls and Okere reported that acute restraint increases varicosity density and decreases intervaricosity length in NADPH-dpositive neurons in the rat dlPAG [90]. The capacity to defend against stress is decreasing with aging. Although there are many reports of relationship between stress and NOS, or NOS and aging, the direct relationship between NO and aging in dlPAG has not been identified. Thus, through further studies, it is expected that the decreased stress response in aging may be related to the action of NO in dlPAG.

\section{Concluding Remarks}

NO and aging are closely related, but more intensive research is necessary to understand this relationship and the functional, anatomical, and molecular mechanisms of agerelated alteration by NO in the CNS. This information will help us understand the mechanisms of both the aging process and neurodegenerative diseases such as Parkinson's disease and Alzheimer's disease. Alterations in the NO system in the aged CNS influence many regions in the rats brains, such as the neuroendocrine system, the visual system, the auditory system, the spinal cord, cognition and learning, the stress response, the salivary system, and the autonomous nervous system. The NO system in each region may influence chemical and structural changes in the CNS during aging. Consecutive neurophysical changes may cause symptoms associated with the CNS aging process, such as change in orientation, attention, and memory. In different parts of the CNS, NADPH-d-positive neurons have different distributions and different effects on the aging process. Additionally, NADPH-d-positive neurons have both protective and toxic effects on the CNS during aging. Therefore, clarifying agerelated and NO-related alterations in the CNS may be helpful in the identification of new therapeutic targets for aging and neurodegenerative diseases.

\section{References}

[1] M. A. Peinado, "Histology and histochemistry of the aging cerebral cortex: an overview," Microscopy Research and Technique, vol. 43, no. 1, pp. 1-7, 1998.

[2] N. A. Bishop, T. Lu, and B. A. Yankner, "Neural mechanisms of ageing and cognitive decline," Nature, vol. 464, no. 7288, pp. 529-535, 2010.

[3] N. P. Kedar, "Can we prevent Parkinson's and Alzheimer's disease?" Journal of Postgraduate Medicine, vol. 49, no. 3, pp. 236-245, 2003.

[4] K. Kitani, C. Minami, W. Maruyama, S. Kanai, G. O. Ivy, and M. C. Carrillo, Critical Reviews of Oxidative Stress and Aging: Advances in Basic Science, Diagnostic and Intervention, World Scientific, Singapore, 2003.

[5] J. A. Knight, "The process and theories of aging," Annals of Clinical and Laboratory Science, vol. 25, no. 1, pp. 1-12, 1995.

[6] I. Paakkari and P. Lindsberg, "Nitric oxide in the central nervous system," Annals of Medicine, vol. 27, no. 3, pp. 369-377, 1995. 
[7] D. S. Bredt and S. H. Snyder, "Transient nitric oxide synthase neurons in embryonic cerebral cortical plate, sensory ganglia, and olfactory epithelium," Neuron, vol. 13, no. 2, pp. 301-313, 1994.

[8] C. L. M. Bon and J. Garthwaite, "Nitric oxide-induced potentiation of CA1 hippocampal synaptic transmission during baseline stimulation is strictly frequency-dependent," Neuropharmacology, vol. 40, no. 4, pp. 501-507, 2001.

[9] M. Zhuo and R. D. Hawkins, "Long-term depression: a learning-related type of synaptic plasticity in the mammalian central nervous system," Reviews in the Neurosciences, vol. 6, no. 3, pp. 259-277, 1995.

[10] A. Law, S. Gauthier, and R. Quirion, "Say NO to Alzheimer's disease: the putative links between nitric oxide and dementia of the Alzheimer's type," Brain Research Reviews, vol. 35, no. 1, pp. 73-96, 2001.

[11] S. M. McCann, J. Licinio, M. L. Wong, W. H. Yu, S. Karanth, and V. Rettorri, “The nitric oxide hypothesis of aging," Experimental Gerontology, vol. 33, no. 7-8, pp. 813-826, 1998.

[12] V. Calabrese, T. E. Bates, and A. M. Giuffrida Stella, "NO synthase and NO dependent signal pathways in brain aging and neurodegenerative disorders: the role of oxidant/antioxidant balance," Neurochemical Research, vol. 25, no. 9-10, pp. 13151341, 2000.

[13] S. Dikalov, "Cross talk between mitochondria and NADPH oxidases," Free Radical Biology and Medicine, vol. 51, no. 7, pp. 1289-1301, 2011.

[14] J. S. Stamler, E. J. Toone, S. A. Lipton, and N. J. Sucher, "(S)NO signals: translocation, regulation, and a consensus motif, Neuron, vol. 18, no. 5, pp. 691-696, 1997.

[15] B. T. Hope, G. J. Michael, K. M. Knigge, and S. R. Vincent, "Neuronal NADPH diaphorase is a nitric oxide synthase," Proceedings of the National Academy of Sciences of the United States of America, vol. 88, no. 7, pp. 2811-2814, 1991.

[16] D. Necchi, M. Virgili, B. Monti, A. Contestabile, and E. Scherini, "Regional alterations of the NO/NOS system in the aging brain: a biochemical, histochemical and immunochemical study in the rat," Brain Research, vol. 933, no. 1, pp. 31-41, 2002.

[17] A. Villena, F. Díaz, L. Vidal, M. Moreno, and I. Pérez De Vargas, "Quantitative age-related changes in NADPH-diaphorase-positive neurons in the ventral lateral geniculate nucleus," Neuroscience Research, vol. 46, no. 1, pp. 63-72, 2003.

[18] T. M. Dawson, D. S. Bredt, M. Fotuhi, P. M. Hwang, and S. H. Snyder, "Nitric oxide synthase and neuronal NADPH diaphorase are identical in brain and peripheral tissues," Proceedings of the National Academy of Sciences of the United States of America, vol. 88, no. 17, pp. 7797-7801, 1991.

[19] T. M. Dawson, V. L. Dawson, and S. H. Snyder, "A novel neuronal messenger molecule in brain: the free radical, nitric oxide," Annals of Neurology, vol. 32, no. 3, pp. 297-311, 1992.

[20] S. R. Vincent and H. Kimura, "Histochemical mapping of nitric oxide synthase in the rat brain," Neuroscience, vol. 46, no. 4, pp. 755-784, 1992.

[21] Y. Huh, C. Kim, W. Lee, J. Kim, and H. Ahn, "Age-related change in the neuropeptide Y and NADPH-diaphorase-positive neurons in the cerebral cortex and striatum of aged rats," Neuroscience Letters, vol. 223, no. 3, pp. 157-160, 1997.

[22] Y. H. Chung, C. M. Shin, K. M. Joo, M. J. Kim, and C. I. Cha, "Immunohistochemical study on the distribution of nitrotyrosine and neuronal nitric oxide synthase in aged rat cerebellum," Brain Research, vol. 951, no. 2, pp. 316-321, 2002.
[23] D. R. Brady, R. G. Carey, and E. J. Mufson, "Reduced nicotinamide adenine dinucleotide phosphate-diaphorase (NADPHd) profiles in the amygdala of human and new world monkey (Saimiri sciureus)," Brain Research, vol. 577, no. 2, pp. 236248, 1992.

[24] I. S. Lolova, S. R. Lolov, and D. E. Itzev, "Changes in NADPH-diaphorase neurons of the rat laterodorsal and pedunculopontine tegmental nuclei in aging," Mechanisms of Ageing and Development, vol. 90, no. 2, pp. 111-128, 1996.

[25] I. S. Lolova, D. E. Itzev, S. R. Lolov, and K. G. Usunoff, "Agerelated changes in the NADPH-diaphorase-positive neuronal perikarya of the dorsolateral column of the periaqueductal gray in the rat," Mechanisms of Ageing and Development, vol. 108, no. 1, pp. 49-59, 1999.

[26] B. A. Pasqualotto and S. R. Vincent, "Galanin and NADPHdiaphorase coexistence in cholinergic neurons of the rat basal forebrain," Brain Research, vol. 551, no. 1-2, pp. 78-86, 1991.

[27] R. G. Cutler, "Antioxidants and aging," American Journal of Clinical Nutrition, vol. 53, no. 1, pp. 373S-379S, 1991.

[28] W. C. Benzing and E. J. Mufson, "Increased number of NADPH-d-positive neurons within the substantia innominata in Alzheimer's disease," Brain Research, vol. 670, no. 2, pp. 351-355, 1995.

[29] J. W. Unger and W. Lange, "NADPH-diaphorase-positive cell populations in the human amygdala and temporal cortex: neuroanatomy, peptidergic characteristics and aspects of aging and Alzheimer's disease," Acta Neuropathologica, vol. 83, no. 6, pp. 636-646, 1992.

[30] R. J. Ferrante, N. W. Kowall, and M. F. Beal, "Selective sparing of a class of striatal neurons in Huntington's disease," Science, vol. 230, no. 4725, pp. 561-563, 1985.

[31] J. Koh and D. W. Choi, "Vulnerability of cultured cortical neurons to damage by excitotoxins: differential susceptibility of neurons containing NADPH-diaphorase," The Journal of Neuroscience, vol. 8, no. 6, pp. 2153-2163, 1988.

[32] J. Y. Koh, S. Peters, and D. W. Choi, "Neurons containing $\mathrm{NADPH}$-diaphorase are selectively resistant to quinolinate toxicity," Science, vol. 234, no. 4772, pp. 73-76, 1986.

[33] R. J. Boegman and A. Parent, "Differential sensitivity of neuropeptide $\mathrm{Y}$, somatostatin and NADPH-diaphorase containing neurons in rat cortex and striatum to quinolinic acid," Brain Research, vol. 445, no. 2, pp. 358-362, 1988.

[34] Y. Huh, C. Kim, J. Cho, W. Lee, J. Kim, and H. Ahn, "Differential effects of aging on NADPH-diaphorase and VIP neurons in cerebral cortex of rats," NeuroReport, vol. 8, no. 13, pp. 2991-2994, 1997.

[35] E. Thomas and A. G. E. Pearse, "The fine localization of dehydrogenases in the nervous system," Histochemie, vol. 2, no. 4, pp. 266-282, 1961.

[36] J. D. Fessenden, D. E. Coling, and J. Schacht, "Detection and characterization of nitric oxide synthase in the mammalian cochlea," Brain Research, vol. 668, no. 1-2, pp. 9-15, 1994.

[37] S. Reuss, D. F. Schaeffer, M. H. Laages, and R. Riemann, "Evidence for increased nitric oxide production in the auditory brain stem of the aged dwarf hamster (Phodopus sungorus): an NADPH-diaphorase histochemical study," Mechanisms of Ageing and Development, vol. 112, no. 2, pp. 125-134, 2000.

[38] R. Druga and J. Syka, "NADPH-diaphorase activity in the central auditory structures of the rat," NeuroReport, vol. 4, no. 8, pp. 999-1002, 1993.

[39] L. Ouda, F. C. Nwabueze-Ogbo, R. Druga, and J. Syka, "NADPH-diaphorase-positive neurons in the auditory cortex 
of young and old rats," NeuroReport, vol. 14, no. 3, pp. 363366, 2003.

[40] K. L. Yu, Y. Tamada, F. Suwa, Y. R. Fang, and C. S. Tang, "Agerelated changes in oxytocin-, arginine vasopressin- and nitric oxide synthase-expressing neurons in the supraoptic nucleus of the rat," Life Sciences, vol. 78, no. 10, pp. 1143-1148, 2006.

[41] D. Sánchez-Zuriaga, N. Martí-Gutiérrez, M. Á. P. De La Cruz, and M. R. Peris-Sanchis, "Age-related changes of NADPHdiaphorase-positive neurons in the rat inferior colliculus and auditory cortex," Microscopy Research and Technique, vol. 70, no. 12, pp. 1051-1059, 2007.

[42] Y. Huh, D. Choon Park, S. Geun Yeo, and C. Cha Il, "Evidence for increased NADPH-diaphorase-positive neurons in the central auditory system of the aged rat," Acta Oto-Laryngologica, vol. 128, no. 6, pp. 648-653, 2008.

[43] O. Manzoni, L. Prezeau, P. Marin, S. Deshager, J. Bockaert, and L. Fagni, "Nitric oxide-induced blockade of NMDA receptors," Neuron, vol. 8, no. 4, pp. 653-662, 1992.

[44] B. Jabłońska, M. Kossut, and J. Skangiel-Kramska, “Transient increase of AMPA and NMDA receptor binding in the barrel cortex of mice after tactile stimulation," Neurobiology of Learning and Memory, vol. 66, no. 1, pp. 36-43, 1996.

[45] H. J. Shim, L. H. Lee, Y. Huh, S. Y. Lee, and S. G. Yeo, "Agerelated changes in the expression of NMDA, serotonin, and GAD in the central auditory system of the rat," Acta OtoLaryngologica, vol. 132, no. 1, pp. 44-50, 2012.

[46] J. J. Lee, Y. W. Cho, Y. Huh, C. I. Cha, and S. G. Yeo, "Effect of nitric oxide on auditory cortical neurons of aged rats," Neuroscience Letters, vol. 447, no. 1, pp. 37-41, 2008.

[47] H. Wakatsuki, H. Gomi, M. Kudoh et al., "Layer-specific NO dependence of long-term potentiation and biased NO release in layer $\mathrm{V}$ in the rat auditory cortex," Journal of Physiology, vol. 513, no. 1, pp. 71-81, 1998.

[48] K. Brauer, W. Schober, and L. Leibnitz, "The ventral lateral geniculate nucleus of the albino rat. Morphological and histochemical observations," Journal für Hirnforschung, vol. 25, no. 2, pp. 205-236, 1984.

[49] A. Ahmad and P. D. Spear, "Effects of aging on the size, density, and number of rhesus monkey lateral geniculate neurons," Journal of Comparative Neurology, vol. 334, no. 4, pp. 631-643, 1993.

[50] L. O. Uttenthal, D. Alonso, A. P. Fernández et al., "Neuronal and inducible nitric oxide synthase and nitrotyrosine immunoreactivities in the cerebral cortex of the aging rat," Microscopy Research and Technique, vol. 43, no. 1, pp. 75-88, 1998.

[51] P. L. A. Gabbott and S. J. Bacon, "Two types of interneuron in the dorsal lateral geniculate nucleus of the rat: a combined NADPH diaphorase histochemical and GABA immunocytochemical study," Journal of Comparative Neurology, vol. 350, no. 2, pp. 281-301, 1994.

[52] S. J. Hwang and Y. Huh, "Age-related changes in nitric oxide synthase in the lateral geniculate nucleus of rats," Journal of Molecular Histology, vol. 41, no. 2-3, pp. 129-135, 2010.

[53] K. J. Berkley, "A life of pelvic pain," Physiology and Behavior, vol. 86, no. 3, pp. 272-280, 2005.

[54] R. N. Ranson, A. L. Dodds, M. J. Smith, R. M. Santer, and A. H. D. Watson, "Age-associated changes in the monoaminergic innervation of rat lumbosacral spinal cord," Brain Research, vol. 972, no. 1-2, pp. 149-158, 2003.

[55] H. C. Yoon, D. Kim, J. L. Keum et al., "Immunohistochemical study on the distribution of neuronal nitric oxide synthaseimmunoreactive neurons in the spinal cord of aged rat," Journal of Molecular Histology, vol. 36, no. 5, pp. 325-329, 2005.
[56] K. Kanda, "Expression of neuronal nitric oxide synthase in spinal motoneurons in aged rats," Neuroscience Letters, vol. 219, no. 1, pp. 41-44, 1996.

[57] H. Tan, J. He, S. Wang et al., "Age-related NADPH-diaphorase positive bodies in the lumbosacral spinal cord of aged rats," Archives of Histology and Cytology, vol. 69, no. 5, pp. 297-310, 2006.

[58] A. Hou-Yu, A. T. Lamme, E. A. Zimmerman, and A. J. Silverman, "Comparative distribution of vasopressin and oxytocin neurons in the rat brain using a double-label procedure," Neuroendocrinology, vol. 44, no. 2, pp. 235-246, 1986.

[59] M. R. Melis, R. Stancampiano, W. Fratta, and A. Argiolas, "Oxytocin concentration changes in different rat brain areas but not in plasma during aging," Neurobiology of Aging, vol. 13, no. 6, pp. 783-786, 1992.

[60] E. Fliers, D. F. Swaab, C. W. Pool, and R. W. H. Verwer, "The vasopressin and oxytocin neurons in the human supraoptic and paraventricular nucleus; changes with aging and in senile denmentia," Brain Research, vol. 342, no. 1, pp. 45-53, 1985.

[61] W. F. Silverman, P. A. Aravich, J. R. Sladek, and C. D. Sladek, "Physiological and biochemical indices of neuropophyseal function in the aging Fischer rat," Neuroendocrinology, vol. 52, no. 2, pp. 181-190, 1990.

[62] S. Yasin, A. Costa, P. Trainer, R. Windle, M. L. Forsling, and A. Grossman, "Nitric oxide modulates the release of vasopressin from rat hypothalamic explants," Endocrinology, vol. 133, no. 3, pp. 1466-1469, 1993.

[63] G. Williams, X. J. Cai, J. C. Elliott, and J. A. Harrold, "Anabolic neuropeptides," Physiology and Behavior, vol. 81, no. 2, pp. 211-222, 2004.

[64] A. Wójcik-Gładysz, T. Misztal, M. Wańkowsk, K. Romanowicz, and J. Polkowska, "Effect of central infusions of neuropeptide $\mathrm{Y}$ on $\mathrm{GnRH} / \mathrm{LH}$ axis in ewes during the early anoestrous period," Reproductive Biology, vol. 3, no. 1, pp. 29-46, 2003.

[65] N. W. Kowall and M. F. Beal, "Cortical somatostatin, neuropeptide $\mathrm{Y}$, and NADPH diaphorase neurons: normal anatomy and alterations in Alzheimer's disease," Annals of Neurology, vol. 23, no. 2, pp. 105-114, 1988.

[66] N. W. Kowall, R. J. Ferrante, and M. F. Beal, "Neuropeptide Y, somatostatin, and reduced nicotinamide adenine dinucleotide phosphate diaphorase in the human striatum: a combined immunocytochemical and enzyme histochemical study," Neuroscience, vol. 20, no. 3, pp. 817-828, 1987.

[67] H. Higuchi, H. Y. T. Yang, and E. Costa, "Age-related bidirectional changes in neuropeptide $\mathrm{Y}$ peptides in rat adrenal glands, brain, and blood," Journal of Neurochemistry, vol. 50, no. 6, pp. 1879-1886, 1988.

[68] C. Kowalski, J. Micheau, R. Corder, R. Gaillard, and B. Conte-Devolx, "Age-related changes in cortico-releasing factor, somatostatin, neuropeptide Y, methionine enkephalin and $\beta$-endorphin in specific rat brain areas," Brain Research, vol. 582, no. 1, pp. 38-46, 1992.

[69] M. A. Casey, "The effects of aging on neuron number in the rat superior olivary complex," Neurobiology of Aging, vol. 11, no. 4, pp. 391-394, 1990.

[70] C. E. Finch, "Neuron atrophy during aging: programmed or sporadic?" Trends in Neurosciences, vol. 16, no. 3, pp. 104-110, 1993.

[71] Y. Huh, W. Lee, J. Cho, and H. Ahn, "Regional changes of NADPH-diaphorase and neuropeptide Y neurons in the cerebral cortex of aged Fischer 344 rats," Neuroscience Letters, vol. 247, no. 2-3, pp. 79-82, 1998. 
[72] J. Fahrenkrug and P. C. Emson, "Vasoactive intestinal polypeptide: functional aspects," British Medical Bulletin, vol. 38, no. 3, pp. 265-270, 1982.

[73] S. I. Said, "Vasoactive intestinal peptide," Journal of Endocrinological Investigation, vol. 9, no. 2, pp. 191-200, 1986.

[74] A. G. Watts and L. W. Swanson, "Efferent projections of the suprachiasmatic nucleus: II. Studies using retrograde transport of fluorescent dyes and simultaneous peptide immunohistochemistry in the rat," Journal of Comparative Neurology, vol. 258, no. 2, pp. 230-252, 1987.

[75] J. S. Andreose, G. Fumagalli, and F. Clementi, "On the effect of ageing on the distribution of vasoactive intestinal polypeptide and calcitonin gene-related peptide in the rat brain," Neuroscience Letters, vol. 171, no. 1-2, pp. 167-171, 1994.

[76] C. A. Chee, B. Roozendaal, D. F. Swaab, E. Goudsmit, and M. Mirmiran, "Vasoactive intestinal polypeptide neuron changes in the senile rat suprachiasmatic nucleus," Neurobiology of Aging, vol. 9, no. 3, pp. 307-312, 1988.

[77] Y. Huh, C. Kim, J. Cho, W. Lee, J. Kim, and H. Ahn, "Differential effects of aging on NADPH-diaphorase and VIP neurons in cerebral cortex of rats," NeuroReport, vol. 8, no. 13, pp. 2991-2994, 1997.

[78] L. A. A. Camargo, J. V. Menani, W. A. Saad, and W. A. Saad, "Interaction between areas of the central nervous system in the control of water intake and arterial pressure in rats," Journal of Physiology, vol. 350, pp. 1-8, 1984.

[79] V. R. Antunes, G. M. P. A. Camargo, R. Saad, W. A. Saad, A. C. Luiz, and L. A. A. Camargo, "Role of angiotensin II and vasopressin receptors within the supraoptic nucleus in water and sodium intake induced by the injection of angiotensin II into the medial septal area," Brazilian Journal of Medical and Biological Research, vol. 31, no. 12, pp. 1597-1600, 1998.

[80] L. Bodner and M. Gorsky, "Parotid gland secretion of the aging rat," Archives of Gerontology and Geriatrics, vol. 22, no. 1, pp. 63-69, 1996.

[81] V. Rettori, A. Lomniczi, J. C. Elverdin et al., "Control of salivary secretion by nitric oxide and its role in neuroimmunomodulation," Annals of the New York Academy of Sciences, vol. 917, pp. 258-267, 2000.

[82] A. Lomniczi, A. M. Suburo, J. C. Elverdin et al., "Role of nitric oxide in salivary secretion," NeuroImmunoModulation, vol. 5, no. 5, pp. 226-233, 1998.

[83] W. A. Saad, I. F. M. S. Guarda, L. A. D. A. Camargo et al., "Novel evidence that nitric oxide of the medial septal area influences the salivary secretion induced by pilocarpine," Life Sciences, vol. 70, no. 20, pp. 2403-2412, 2002.

[84] W. A. Saad, L. I. Gutierrez, I. F. M. Siqueira Guarda et al., "Nitric oxide of the supraoptic nucleus influences the salivary secretion, sodium renal excretion, urinary volume and arterial blood pressure induced by pilocarpine," Life Sciences, vol. 74, no. 13, pp. 1593-1603, 2004.

[85] T. Tanaka, Y. Tamada, and F. Suwa, "Influence of age-related changes in nitric oxide synthase-expressing neurons in the rat supraoptic nucleus on inhibition of salivary secretion," Okajimas Folia Anatomica Japonica, vol. 84, no. 4, pp. 125-131, 2008.

[86] S. R. Vincent and H. Kimura, "Histochemical mapping of nitric oxide synthase in the rat brain," Neuroscience, vol. 46, no. 4, pp. 755-784, 1992.

[87] I. S. Lolova, D. E. Itzev, S. R. Lolov, and K. G. Usunoff, "Agerelated changes in the NADPH-diaphorase-positive neuronal perikarya of the dorsolateral column of the periaqueductal gray in the rat," Mechanisms of Ageing and Development, vol. 108, no. 1, pp. 49-59, 1999.
[88] A. Bocheva, E. Dzambazova, B. Landzhov, and A. BozhilovaPastirova, "Influence of Tyr-W-MIF-1 and Tyr-K-MIF-1 on nitric oxide synthase and tyrosine hydroxylase expression in periaqueductal gray after three stress models in rats," Comptes Rendus de L'Academie Bulgare des Sciences, vol. 61, no. 4, pp. 535-542, 2008.

[89] E. B. Dzambazova, B. V. Landzhov, A. I. Bocheva, and A. A. Bozhilova-Pastirova, "Effects of D-kyotorphin on nociception and NADPH-d neurons in rat's periaqueductal gray after immobilization stress," Amino Acids, vol. 41, no. 4, pp. 937-944, 2011.

[90] S. L. Smalls and C. O. Okere, "acute restraint increases varicosity density and reduces the inter-varicosity distance in NADPH diaphorase-containing neurons in the rat dorsolateral periaqueductal gray matter," Neuroscience Letters, vol. 511, no. 1, pp. 23-27, 2012. 


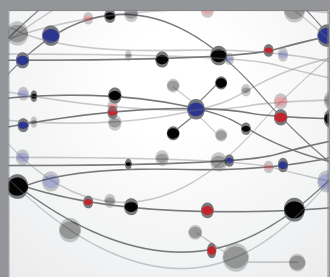

The Scientific World Journal
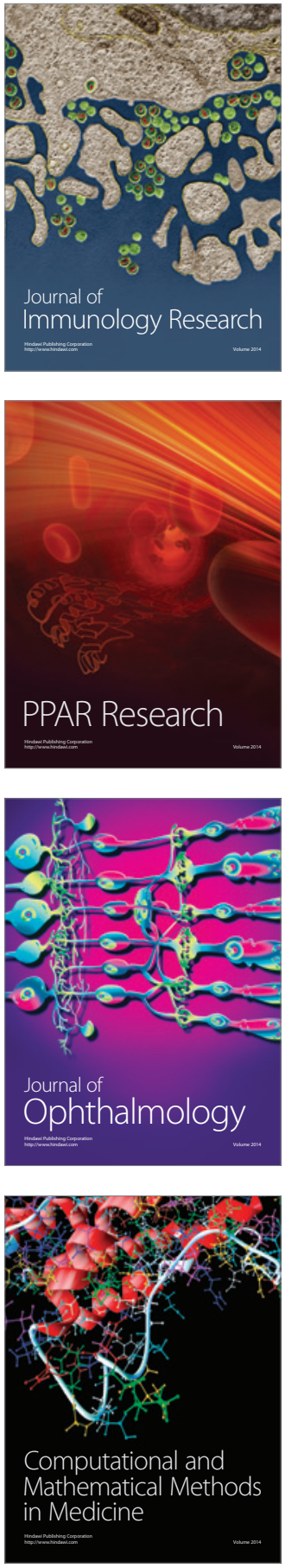

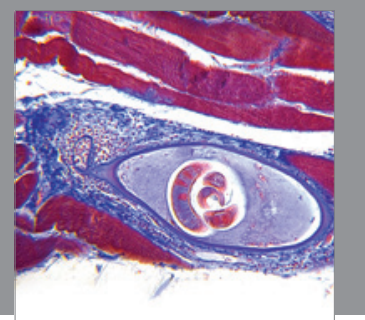

Gastroenterology

Research and Practice
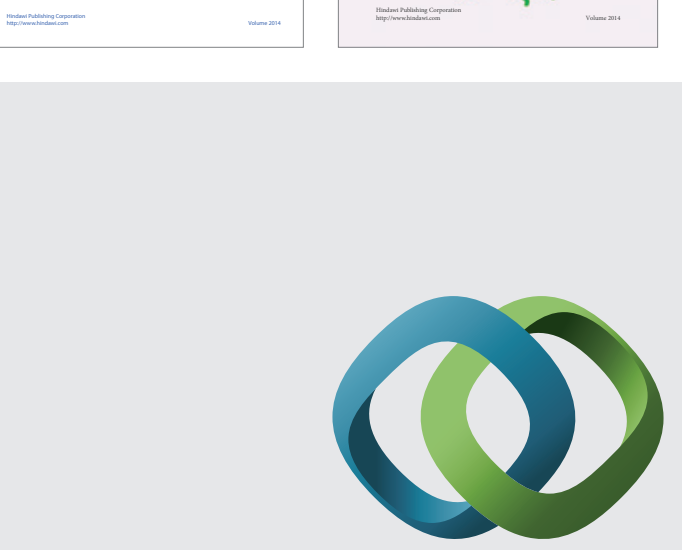

\section{Hindawi}

Submit your manuscripts at

http://www.hindawi.com
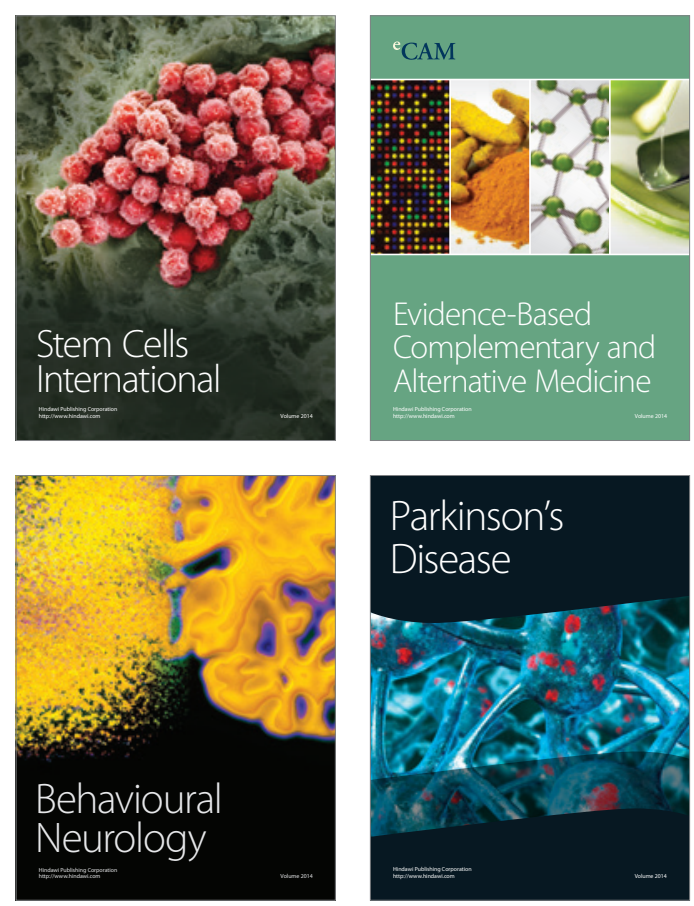

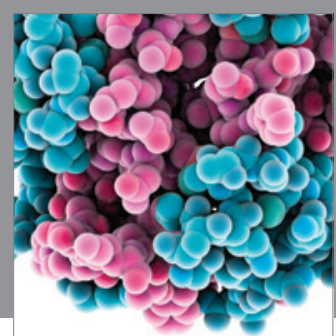

Journal of
Diabetes Research

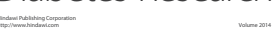

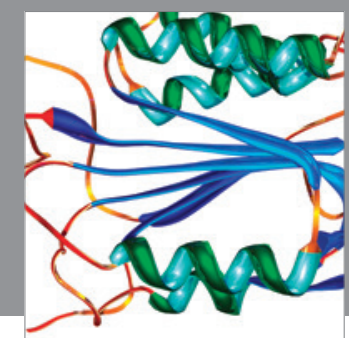

Disease Markers
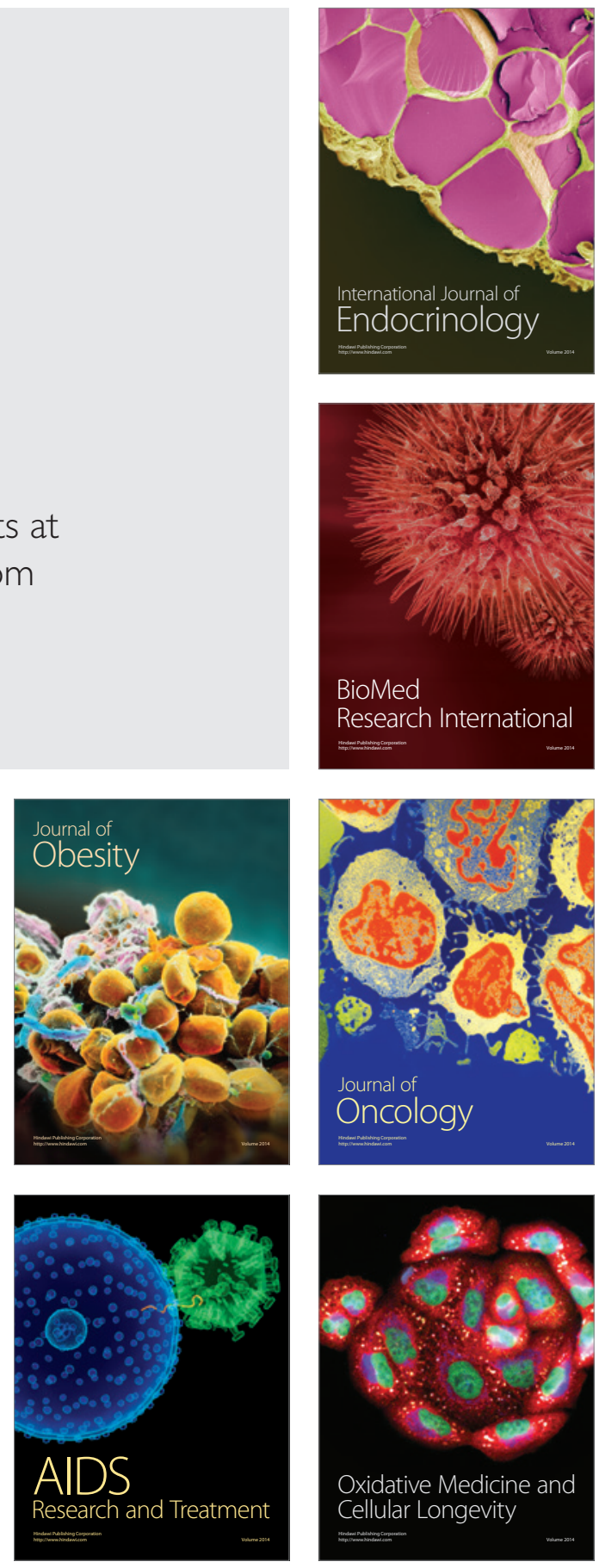